After the winter quarters had been prepared, it was the intention of Holm to examine the fiord of Fredericksthal, and the region between it and Tasermint, which has not yet been explored with care.

It was his intention to start for the eastern coast about the end of April, or early in May, 1884; and during the winter of 1884-85 some members of the party were to remain there.

\section{HUMIDITY AND CHRONOMETER RATES.}

Major-Gen. J. F. Tennant, of her Majesty's mint, Calcutta, communicated to the Royal astronomical society in November last a paper on humidity as a cause of variation in the rate of chronometers. He had borrowed from the government-stores about the end of March, 1882, a chronometer, by Fletcher of London, which had been some time in India, but had not been cleaned since its arrival, and was said to have a good rate. From a gainingrate of $6 \mathrm{~s} .5$, which it preserved fairly well for about two months, it suddenly fell to a gaining-rate of $2 \mathrm{s.} 0$; this being the commencement of a succession of rather abnormal fluctuations of rate which Major Tennant carefully observed and recorded for about eighteen months. These rates were first compared with a plot of the published daily mean temperatures of the meteorological observatory, with results not quite satisfactory; for, though it would seem at first sight that the rate depends on temperature, further examination showed that it can do so to a moderate extent only, and confirmed the belief, which Major Tennant had from general impressions, that rate does not depend on temperature. The extraordinary differences of rate at times of nearly equal temperature leave no doubt that there is a periodic change of rate; and the cause of this, Major Tennant believes to be humidity. His first suspicion of this was raised by the sudden fall in rate of this chronometer, in 1883 , being coincident with the first heavy rains producing great damp; and by the fact, also, that the same thing occurred the year previous, and that the whole period of low gaining-rate was that of the rains, while the lowest was the warm time at the end of the rains, when the soil is generally loaded with moisture. The same phenomenon recurred. It is, however, much more difficult to compare the supposed cause and effect without special arrangements; and, in any case, it is doubtful whether air-humidity could be more than a rough guide.

If the oil in the arbors of the balance be hygroscopic, it is easy to see that it may become more fluid in damp weather, the are of oscillation will increase, the balance-vibration take longer, and the chronometer lose; but the momentary humidity of the air will not correspond to the rate, as the temperature does more or less. Major Tennant, remarking the undoubted connection in this particular case, suggests special experimenting in the following directions:-

10. Are chronometer-oils, or any of them, hygroscopic? $2^{\circ}$. Can they become so by exposure to a tropical climate?

In this latter case he conceives that the climatic influence cannot be imitated in Europe. The effect of the heat, and probably the light, are very destructive of some materials. Vulcanized india-rubber, for example, does not bear exposure in India, though it seems to answer in Europe, even in heat and damp.

Lastly, in estimating the effect of humidity on a given chronometer, it will probably be best to use one of the old hair or grass hygroscopes for the humidity, placing it in the case, enclosed with the chronometer.

DAVID P. TODD.

\section{THE GREAT COMET OF 1882.}

THIs comet is one of the most interesting that has appeared for a number of years, owing to its very near approach to the sun-surface, and the resemblance of its orbit to the two great comets of 1843 and 1880. It was a brilliant object in the morning sky in September, 1882. Calculations of the orbit have been made recently by Dr. Morrison, Professor Frisby, and Dr. Kreutz. The periods obtained are as follows: Dr. Morrison, 712.1 years; Professor Frisby, 793.9; Dr. Kreutz, 843.1. These periods are, however, somewhat uncertain, owing to the peculiar nature of the nucleus of this comet. Instead of being a single bright body, there appeared to be a row of small nuclei, so that it was a mere matter of judgment with the observer what part of the comet he should observe. The observations were naturally made upon the middle of the row of points, and it is not possible to say with certainty that this corresponded to the centre of gravity of the comet. It is worthy of note, that bright comets are recorded in the year $370 \mathrm{~B}$. C. and in A.D. 1132, both of which could be reconciled with the great comet of 1882 by supposing the period of 751 years.

\section{THE WORK OF THE CAMBRIDGE ARCHAEOLOGICAL MUSEUM.}

THE trustees of the museum of American archaeology and ethnology, founded by George Peabody, held their annual meeting on the 18th of February, the anniversary of the birth of the founder. The Hon. Robert C. Winthrop, president of the board, presided; and Professor Asa Gray, Dr. Henry Wheatland, Mr. John C. Phillips, Mr. Samuel H. Scudder, and Mr. F. W. Putnam (the curator of the museum) were present. The Hon. Stephen Salisbury of Worcester was prevented by temporary illness from attending, and the Hon. Theodore Lyman was unable to leave his duties in Congress.

The report of the treasurer, Mr. Phillips, showed that the $\$ 150,000$ given by $\mathrm{Mr}$. Peabody is well invested. Of the income of $\$ 8,334$, only $\$ 5,186.50$ was expended on account of the museum: $\$ 3,110$ belonged to the building-fund, and the remaining $\$ 37.50$ was expended on insurance. Mr. Winthrop 